\title{
OPTICALLY-ACTIVATED GaAs SWITCHES FOR GROUND PENETRATING RADAR AND FIRING SET APPLICATIONS ${ }^{*}$
}

\author{
G. M. Loubriel, J. Aurand, ${ }^{\dagger}$ G. J. Denison, L. F. Rinehart, D. J. Brown, ${ }^{\ddagger}$ \\ F. J. Zutavern, A. Mar, M. W. O'Malley, and W. D. Helgeson \\ High Power Electromagnetics Department \\ Sandia National Laboratories \\ Albuquerque, NM 87185-1153 \\ L. Carin \\ Department of Electrical and Computer Engineering \\ Duke University, Durham, NC 27708-0291
}

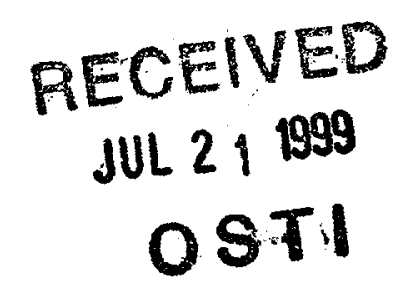

\section{Abstract}

Optically activated, high gain GaAs switches are being tested for many different applications. Two such applications are ground penetrating radar (GPR) and firing set switches. The ability of high gain GaAs Photoconductive Semiconductor Switches (PCSS) to deliver fast risetime pulses makes them suitable for their use in radars that rely on fast impulses. This type of direct time domain radar is uniquely suited for the detection of buried items because it can operate at low frequency, high average power, and close to the ground, greatly increasing power on target. We have demonstrated that a PCSS based system can be used to produce a bipolar waveform with a total duration of about $6 \mathrm{~ns}$ and with minimal ringing. Such a pulse is radiated and returns from a 55 gallon drum will be presented. For firing sets, the switch requirements include small size, high current, dc charging, radiation hardness and modest longevity. We have switched $1 \mathrm{kA}$ at $1 \mathrm{kV}$ and $2.8 \mathrm{kA}$ at $3 \mathrm{kV}$ dc charge.

\section{INTRODUCTION}

Our research has focused on optically triggered, high gain GaAs photoconductive semiconductor switches (PCSS) for pulsed power applications.[1] Table I shows the best results obtained with the switches. The GaAs switches used in this experiment are lateral switches made from undoped $\mathrm{GaAs}$ of high resistivity $>10^{7} \Omega-\mathrm{cm}$ and metallic lands that connect the switch to an energy source and a load. At electric fields above 4 to $6 \mathrm{kV} / \mathrm{cm}$ these switches exhibit high gain.[2,3] We have used trigger energies as low as $180 \mathrm{~nJ}$ to deliver $48 \mathrm{MW}$ in a $30-50 \Omega$ system.[4] In the "on" state the field across the switch stabilizes to a constant called the lock-on field.
Table I: Results of Tests with High Gain GaAs Switches

\begin{tabular}{|l|c|c|}
\hline \multicolumn{1}{|c|}{ Parameter } & Best Values & System results \\
\hline Switch Voltage (kV) & 155 & 100 \\
\hline Switch Current (kA) & 7.0 & 1.26 \\
\hline Peak Power (MW) & 120 & 48 \\
\hline Rise time (ps) & 430 & 430 \\
\hline Trigger Energy (nJ) & 2 & 180 \\
\hline Repetition Rate (kHz) & 40,000 & 1 \\
\hline Lifetime (\# pulses) & $>5 \times 10^{7}$ & $5 \times 10^{4}(77 \mathrm{kV})$ \\
\hline
\end{tabular}

Table I. The middle column describes the best individual results for each parameter and are not simultaneous. The last column describes the result of a single experiment.

\section{GROUND PENETRATING RADAR}

We seek to develop a GPR system that can be utilized for environmental site reconnaissance and, in particular, for finding buried metallic objects such as 55 gallon drums at depths of up to $10 \mathrm{~m}$ (and other man-made objects at various depths) in real soils. The primary disadvantages of GPR have been low penetration depth and low signal to clutter. We hope to minimize both of these problems. The penetration depth will be augmented by using: 1) high peak power, high repetition rate operation for high average power; 2) low center frequencies that better penetrate the ground; and 3) shor duration impulses. The latter allow for the use of low platforms that increase the power on target relative to a high flying platform (due to the $\mathrm{R}^{4}$ term in the radar equation, where $\mathrm{R}$ is the range to the target). Clutter is minimized by time gating the surface clutter return and using low frequencies (since natural objects are smaller than the wavelengths used here and their cross section is smaller than for higher frequency systems). The factor that makes this work unique is that we will utilize direct

\footnotetext{
* This work was supported by the U.S. Department of Energy (DOE) under contract DE-AC04-94AL85000. Sandia is a multiprogram laboratory operated by Sandia Corporation, a Lockheed Martin Company, for the U. S. DOE.

$\dagger$ Presently at the Department of Electrical and Computer Engineering, University of New Mexico, Albuquerque, NM.

¥ Ktech Corporation, 2201 Buena Vista S.E., Albuquerque, NM 87106-4265.
} 


\section{DISCLAIMER}

This report was prepared as an account of work sponsored by an agency of the United States Government. Neither the United States Government nor any agency thereof, nor any of their employees, make any warranty, express or implied, or assumes any legal liability or responsibility for the accuracy, completeness, or usefulness of any information, apparatus, product, or process disclosed, or represents that its use would not infringe privately owned rights. Reference herein to any specific commercial product, process, or service by trade name, trademark, manufacturer, or otherwise does not necessarily constitute or imply its endorsement, recommendation, or favoring by the United States Government or any agency thereof. The views and opinions of authors expressed herein do not necessarily state or reflect those of the United States Government or any agency thereof. 


\section{DISCLAIMER}

Portions of this document may be illegible in electronic image products. Images are produced from the best available original document. 
time domain radar at low frequency and high average power. The soils we intend to study are clay soils with high water content ( 10 to 20 percent, by weight). Detection of drums buried in non water bearing soils or in sand is relatively easy and, thus, will not be discussed.

\section{A. Method of Moments (MoM) Model}

We used a Method of Moments (MoM) model [4] (developed by Dr. L. Carin at Duke University) as a foundation to calculate the expected returns from a buried 55 gallon drum. A tool for the study of electromagnetic scattering from buried objects is the finite difference time domain (FDTD) algorithm which allows scattering to be calculated from rather general environments. However, the FDTD method requires one to grid the entire computational space and, thus, the available computer memory limits the problems it can tackle. The MoM only requires a grid at the target surface while the surrounding media is characterized by a Green's function (which is known for lossy layered media). Also, since MoM is a purely numerical algorithm, it provides insights such as the determination of complex resonant frequencies of targets that are the poles in the MoM solution. The figures show the results of the MoM calculation. Figure 1 and 2 are time and frequency representations of transmitted pulse which has a center frequency of 250 $\mathrm{MHz}$ and peak to peak amplitude of 1.5. We calculated returns for drums buried on their side and upright. The results for the worst case are shown in figures 3 (time domain) and 4 (frequency) for an upright 55 Gallon Drum buried $3 \mathrm{~m}$ in Puerto Rico soil (10\% water content) for normal incidence. Note that the frequency is shifted down and that the peak amplitude is only 0.0045 . Thus, it is crucial to radiate high voltages to receive large signals above the noise threshold for water bearing soils.

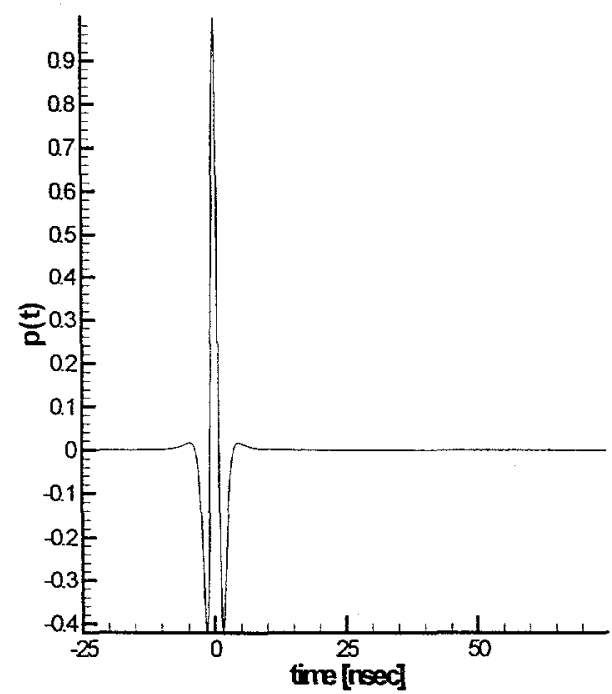

Figure 1: The radiated pulse as modeled in the MoM calculations.

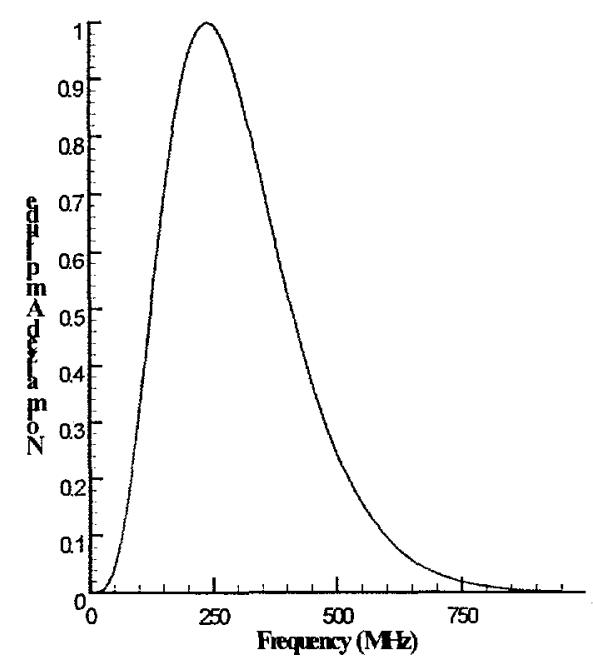

Figure 2: The frequency content of the radiated pulse modeled in the MoM calculations.

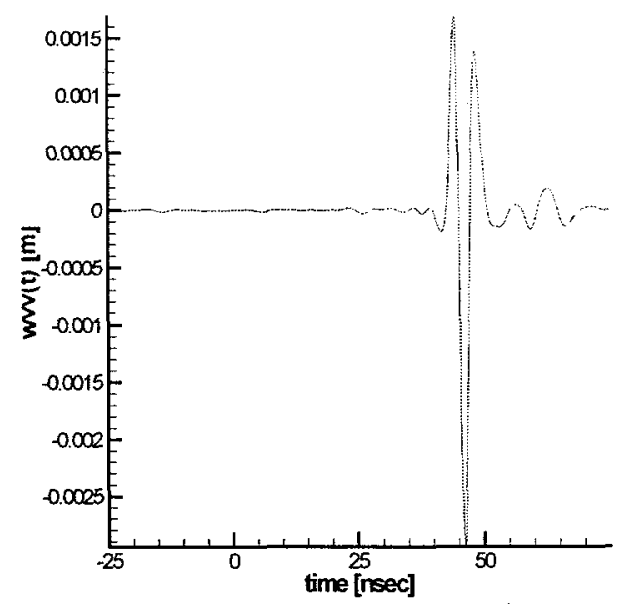

Figure 3: The calculated (MoM) return from an upright drum buried $3 \mathrm{~m}$ deep.

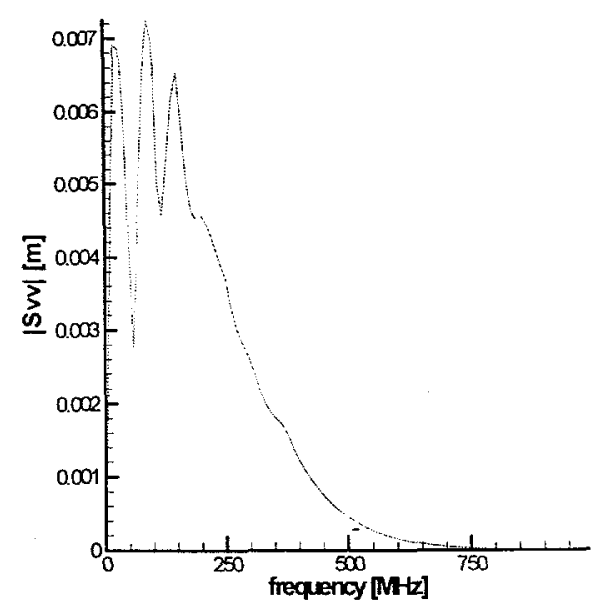

Figure 4: The frequency content of the calculated return. 
The MoM calculations were continued so that we could calculate the expected returns from our antenna and pulser. Figure 5 shows the transmitted pulse from our system and the fitted Raleigh pulse that was used in the calculations. We calculated returns from a single drum buried in Puerto Rico clay soil with $10 \%$ water content in different configurations: 1) a vertical or standing drum whose top is either $1 \mathrm{~m}, 2 \mathrm{~m}$, or $3 \mathrm{~m}$ below the surface, 2) a horizontal or laying-down drum whose top is at either $0.7,1.7$, or $2.7 \mathrm{~m}$ below the surface and aligned parallel to the radiated electric field, and 3 ) a horizontal drum also at the same depths but aligned perpendicular to the radiated electric field. A few of these results are shown in figure 6. First, we want to stress that the returns from the horizontal drums do not depend greatly on polarization. We were concerned with polarization differences that would complicate field searches but that concerns us no longer. Second, the peak amplitudes, in figure 6, for the return relative to the transmitted pulse are as follows: $1.2 \%$ for the $2 \mathrm{~m}$ vertical drum, $0.42 \%$ and $0.40 \%$ for the horizontal drums at $2.7 \mathrm{~m}$, and $0.32 \%$ for the vertical drum at $3 \mathrm{~m}$. Since we can conservatively design a receive system that allows for $60 \mathrm{db}$ to $80 \mathrm{db}$ sensitivity, the above numbers ( $38 \mathrm{db}, 47 \mathrm{db}, 48 \mathrm{db}$, and $50 \mathrm{db}$ ) imply that the system we designed is reasonable for the detection of 55-gallon drums in different types of soils, including highly lossy soils such as Puerto Rico clay with $10 \%$ water content.

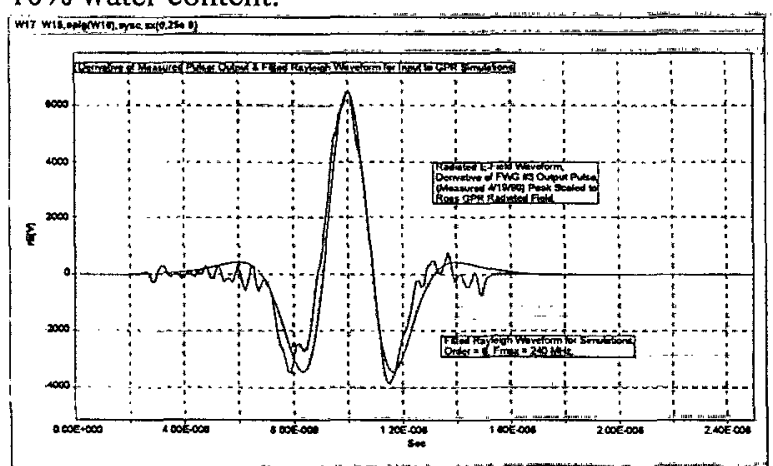

Figure 5: Comparison of modeled waveform and actual transmitted pulse.

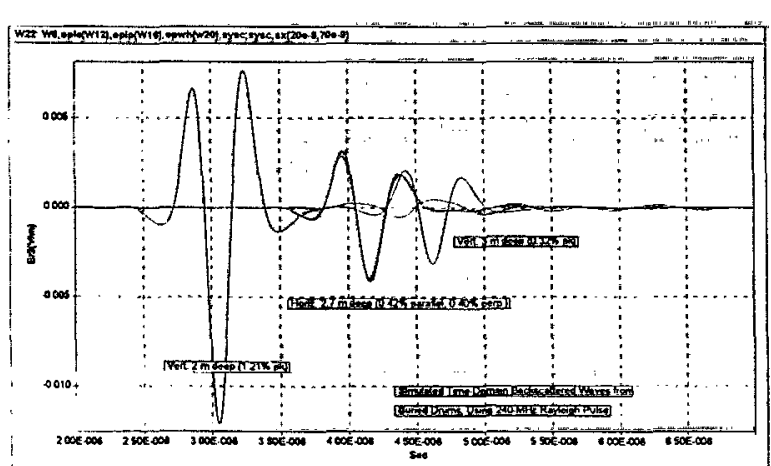

Figure 6: Returns from the various configurations: $2 \mathrm{~m}$ vertical drum, $2.7 \mathrm{~m}$ horizontal drum (parallel and perpendicular polarizations), and $3 \mathrm{~m}$ vertical drum.

\section{B. Experiments}

We tested the system with the drum in air (not buried), as shown in figure 7. Here we used a TEM horn transmit antenna with flared aperture plates and a high-voltage coaxial balun as the input section. The transmitted pulse has already been shown in figure 5 and has peak frequency content at $\sim 260 \mathrm{MHz}$ with $-10 \mathrm{db}$ points at 80 $\mathrm{MHz}$ and at $420 \mathrm{MHz}$ and a transmitted field of $11 \mathrm{kV} / \mathrm{m}$ at $1 \mathrm{~m}$ when the pulser was charged to $30 \mathrm{kV}$. Note that the EM size of a drum is $\sim 3 \mathrm{~ns}$ in air $(\varepsilon=1,330 \mathrm{MHz})$ and $6.7 \mathrm{~ns}$ in soil $(\varepsilon=5,150 \mathrm{MHz})$. We tested different receivers: a B-dot monitor (Figure 8), a calibrated D-dot monitor, and a ridge-horn antenna. The results from the D-dot free field sensor show that the receive field was about $30 \mathrm{~V} / \mathrm{m}$ which was easily detectable (we had to attenuate the signal) and of the order of $15 \mathrm{~V}$. Thus, attenuations of $0.32 \%$ still allow for amplitudes of $\sim 50$ $\mathrm{mV}$ which we will be able to detect. The transmitted pulse was obtained with a PCSS-driven Frozen Wave Generator (with and without a crowbar switch) pulse forming line.

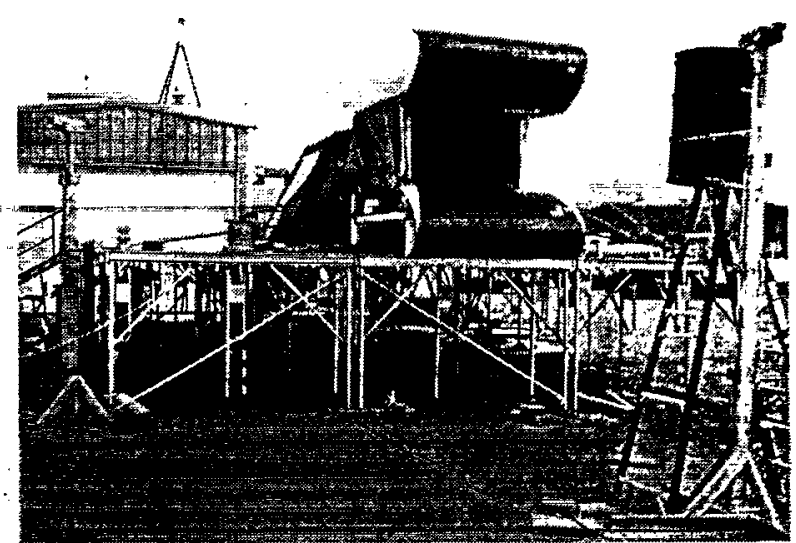

Figure 7: Photo of system demo in air. Note the 55-gallon drum (right) and receiver (left) which are elevated with wood stands.

\section{Reflected Return}

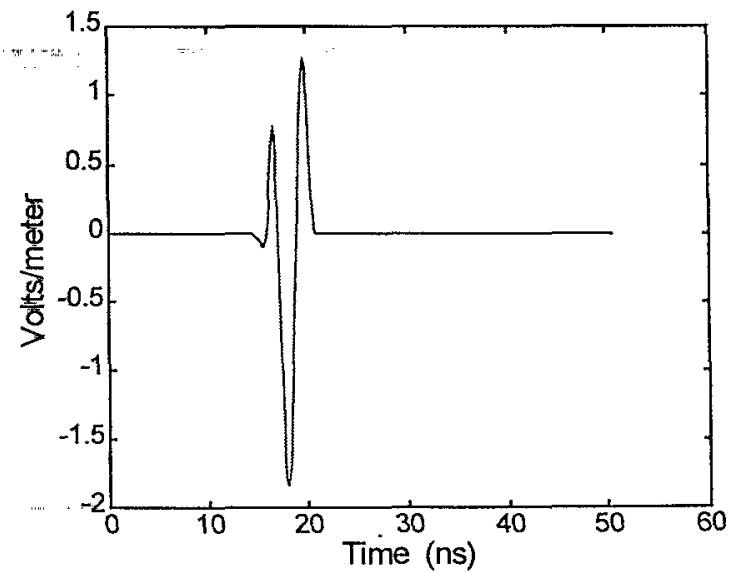

Fig 8: Receive waveform for the B-dot receiver. 


\section{FIRING SETS}

The filamentary nature of the current in a PCSS and the current pinching at the metal to semiconductor interface produce very high current densities at the metalsemiconductor interface. We believe that longevity is determined by the current pinching at the GaAs to metal interface. We have improved [5] longevity by spreading the current along the width of the contact and by making the current spread into the GaAs' depth at low currents $(\sim 10 \mathrm{~A})$ and short pulses $(3.5 \mathrm{~ns})$. For firing sets we are interested in currents that range from $80 \mathrm{~A}$ to $3 \mathrm{kA}$ and pulse durations that are as high as a few $100 \mathrm{~ns}$. One way to achieve increased longevity is to spread the current into multiple filaments. Figure 9 shows the images of current filaments. On the left the switch was triggered as to produce multiple filaments while on the right, the more normal trigger geometry produces a strong, sharp filament. Longevity tests were carried out both ways, at low and high currents. The diffused triggering geometry shows improvement at low currents but not at $1 \mathrm{kV} / \mathrm{l} \mathrm{kA}$.

Another mechanism that has shown improvements in longevity is neutron irradiation. The great advantage of the neutron irradiation is that it also improves radiation hardness. We have used neutron irradiated GaAs to a dose of 1 E14 rads to obtain well over 1,000 pulses in forward biased switches at $80 \mathrm{~A}$ and over 300 pulses with reverse biased switches. We are currently testing whether a PCSS could trigger a main firing set switch and tested the longevity of the PCSS and the system jitter under these conditions. We tested $400 \mu \mathrm{m}$ gap switches forward and reverse biased with neutron doses of $1 \mathrm{E} 14$ and $3 \mathrm{E}$ 14 rads and $0.5 \mathrm{~mm}$ gap $\mathrm{n}-\mathrm{i}-\mathrm{n}$ switches and they all survived for more than 1,000 pulses. At current levels of $80 \mathrm{~A}$, we obtained excellent longevity for this application two different ways: 1) p-i-n forward biased switch (400 $\mu \mathrm{m}$ gap) at $480 \mathrm{~V}$ and obtained 2,000 pulses. 2) $\mathrm{n}-\mathrm{i}-\mathrm{n}$ switch, $500 \mu \mathrm{m}$ gap, $540 \mathrm{~V},>10,000$ shots $(>700 \mathrm{~V}$ holdoff). The system jitter was also tested in a variety of ways and values that range from $1.55 \mathrm{~ns}$ to $2.71 \mathrm{~ns}$ were obtained. The peak current delivered to the main firing set switch is heavily dependent on inductance. Two circuits were tested: a large strip line circuit with $\mathrm{C}=2$ $\mathrm{nF}, \mathrm{L}=30 \mathrm{nH}$ that resulted in $80 \mathrm{~A}$ at $500 \mathrm{~V}$ and a small (see figure 10), low inductance, $\mathrm{CDU}$ tester circuit $\mathrm{C}=1.4$ $\mathrm{nF}, \mathrm{L}=3.8 \mathrm{nH}$ that also gave $80 \mathrm{~A}$ but at $240 \mathrm{~V}$.
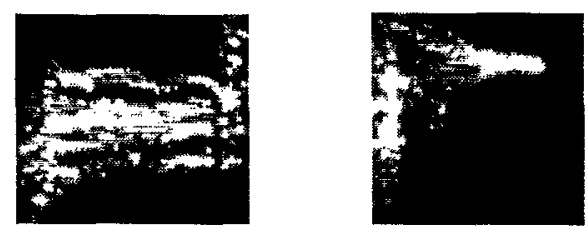

Figure 9. Infrared images of the switch during conduction showing multiple, diffuse filaments at left and a strong filament on the right. The outline of the metal contacts runs top to bottom in the figures and they are separated by $400 \mu \mathrm{m}$. The current was $40 \mathrm{~A}$.

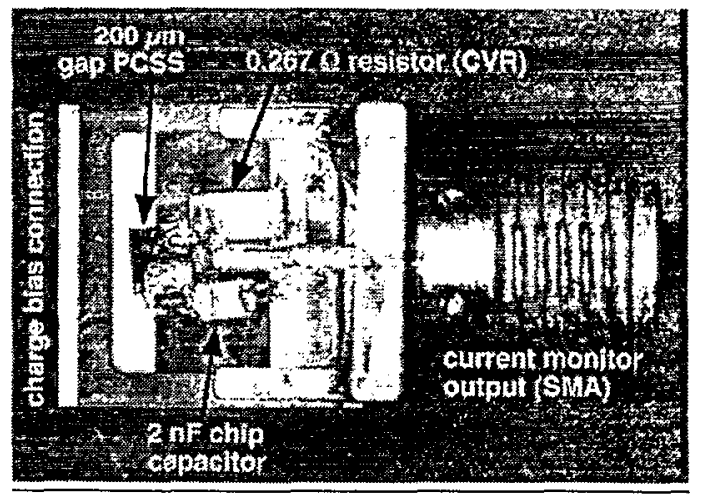

Figure 10. Small (the SMA connector on the right is 2 $\mathrm{mm}$ in diameter), low inductance $(\mathrm{L}=3.8 \mathrm{nH})$ circuit.

\section{SUMMARY}

Optically activated, high gain GaAs switches were tested for ground penetrating radar and firing set switches. We have demonstrated that a PCSS based system can be used to produce a bipolar waveform with a total duration of about $6 \mathrm{~ns}$ and with minimal ringing. Such a pulse is radiated and returns from a 55 gallon drum obtained. For firing sets, the switch requirements include small size. high current, dc charging, radiation hardness and modest longevity. We have switched $1 \mathrm{kA}$ at $1 \mathrm{kV}$ and $2.8 \mathrm{kA}$ at $3 \mathrm{kV} \mathrm{dc}$ charge.

\section{REFERENCES}

[1] For papers on high gain PCSS see: High-Power Optically Activated Solid- State Switches, A. Rosen and F. J. Zutavern, Eds., Artech House, Boston, 1993.

[2] G. M. Loubriel et al, "Toward pulsed power uses for photoconductive semiconductor switches: closing switches," Proc. 6th IEEE Pulsed Power Conf., (IEEE. NY, 1987), Arlington, VA, 1987, pp. 145-148.

[3] F. J. Zutavern et al, "Recent developments in opening photoconductive semiconductor switches," Proc. 6th IEEE Pulsed Power Conf., (IEEE, NY, 1987), Arlington. VA, 1987, pp. 577-580.

[4] G. M. Loubriel et al, "High Gain GaAs Photoconductive Semiconductor Switches for Impulse Sources," Proc. SPIE Optically Activated Switching Conference IV, SPIE Proc. Series Vol. 2343, pp. 180-186, Boston, MA, 1994.

[5] A. Mar et al, Proc. 12th IEEE Pulsed Power Conf. (IEEE, NY, 1999), Monterrey, CA, 1999, this conference. 